\title{
ANÁLISE GEOGRÁFICA DA COVID-19 EM MARINGÁ/PR
}

\section{GEOGRAFICAL ANALYSIS OF COVID-19 IN THE CITY OF MARINGÁ/PR}

\author{
Oseias da Silva Martinuci \\ Docente do Programa de Pós-Graduação em Geografia \\ Universidade Estadual de Maringá/PR \\ osmartinuci@uem.br \\ Udelysses Janete Veltrini Fonzar \\ Docente do Departamento de Medicina \\ Unicesumar/Maringá/PR \\ janetefonzar@hotmail.com \\ Jair Francisco Pestana Biatto \\ Secretário Municipal de Saúde de Maringá \\ jairfpbiatto@hotmail.com \\ Ícaro da Costa Francisco \\ Graduando do Curso de Geografia \\ Universidade Estadual de Maringá/PR \\ icarodacostafran@hotmail.com \\ Ingrid Januário Augusto \\ Graduando do Curso de Geografia \\ Universidade Estadual de Maringá/PR \\ ingrid16januario16@gmail.com \\ Bianca Diana Gazola \\ Graduando do Curso de Geografia \\ Universidade Estadual de Maringá/PR \\ bdgazola@gmail.com
}

\section{RESUMO}

O presente artigo objetiva caracterizar e analisar a introdução do vírus SARS-CoV-2, causador da Covid-19, na cidade de Maringá-PR. Maringá é a segunda maior cidade do interior do estado e, como cidade média, desempenha importantes papéis regionais. Estudos e análises preliminares indicam que a doença se dissemina no território estreitamente associada às estruturas espaciais preexistentes. Os eixos econômicos mais vigorosos, identificados pelas rodovias de maior fluxo e as cidades com destacados papeis regionais, que sediam aeroportos com voos comerciais, modulam significativamente a direção e a intensidade nos novos casos. Apesar de se tratar de uma cidade específica no interior do Paraná, no presente texto podem ser reconhecidos padrões espaciais, processos e dinâmicas que conectam e determinam diferentes territórios. Para tratar dessas questões, o texto está composto por três partes: 1) contextualização da situação geográfica de Maringá; 2) caracterização e análise dos dados de casos confirmados e notificados no período de 18/03/2020 a 30/04/2020, e; 3) Análise dos principais fatores de risco à Covid-19 na escala intraurbana. A análise permite concluir que: 1) os primeiros casos confirmados na cidade de Maringá foram importados diretamente do exterior, sem mediação de São Paulo ou Curitiba; 2) No primeiro mês, os casos estiveram fortemente concentrados nas áreas mais valorizadas, onde se situam as classes com os maiores rendimentos; 3) Após o primeiro mês, contado a partir da confirmação do primeiro caso, iniciou-se a tendência de dispersão para as áreas mais vulneráveis da cidade. Esta breve análise fornece importantes características geográficas de processos pandêmicos, sua configuração e dinâmica espacial na escala intraurbana. Além disso, contém elementos importantes para pesquisas futuras não só da Covid-19, mas de eventos de saúde de modo geral.

Palavras-chave: Geografia. Covid-19. Espaço Urbano. Maringá. Brasil.

Recebido em: 28/04/2020

Aceito para publicação em: 02/06/2020. 


\begin{abstract}
This article aims to characterize and analyze the introduction of the SARS-CoV-2 virus, which causes Covid-19, in the city of Maringá-PR. Maringá is the second largest city in the interior of the state and, as a medium city, plays important regional roles. Preliminary studies and analyzes indicate that the disease spreads in the territory closely associated with pre-existing spatial structures. The most vigorous economic axes, identified by highflow highways and cities with prominent regional roles, which host airports with commercial flights, significantly modulate the direction and intensity in the new cases. Despite being a specific city in the interior of Paraná, in this text, spatial patterns, processes and dynamics that connect and determine different territories can be recognized. To address these issues, the text consists of three parts: 1) contextualizing the geographical situation of Maringá; 2) characterization and analysis of data from confirmed and reported cases from 03/18/2020 to 04/30/2020, and; 3) Analysis of the main risk factors for Covid-19 on the intra-urban scale. The analysis allows to conclude that: 1) the first confirmed cases in the city of Maringá were imported directly from abroad, without mediation from São Paulo or Curitiba; 2) In the first month, the cases were strongly concentrated in the most valued areas, where the classes with the highest income are located; 3 ) After the first month, counting from the confirmation of the first case, the trend of dispersion to the most vulnerable areas of the city began. This brief analysis provides important geographical characteristics of pandemic processes, their configuration and spatial dynamics on the intra-urban scale. In addition, it contains important elements for future research not only at Covid-19, but at health events in general.
\end{abstract}

Keywords: Geography. Covid-19. Urban Space. Maringá. Brazil.

\title{
INTRODUÇÃO
}

Em dezembro de 2019, pesquisadores identificaram uma nova cepa de vírus, mais especificamente uma mutação do coronavírus que o Comitê Internacional de Taxonomia de Vírus designou como "Coronavírus 2 da Síndrome Respiratória Aguda Grave" (SARS-CoV-2) (PREM et al, 2020). O vírus surgiu na cidade de Wuhan, um dos mais importantes centros industriais da China, com população superior a 11 milhões de habitantes, de onde se disseminou rapidamente. A situação geográfica de Wuhan, com importantes conexões aeroviárias para todos os continentes, bem como ligações ferroviárias com a Europa e com todo território chinês, constituiu as condições ideias para a propagação do vírus.

Em fevereiro, a Covid-19 já era transmitida comunitariamente nos países europeus e, ao mesmo tempo, chegava às terras brasileiras. O primeiro caso no Brasil foi confirmado em 26 de fevereiro de 2020. Logo em seguida, novos casos foram sendo confirmados em várias outras cidades. $A$ análise e mapeamento dos dados evidencia uma estreita associação entre a transmissibilidade do vírus e os espaços de maior fluidez. A Covid-19, portanto, disseminou-se pelo mundo atrelada aos espaços geográficos mais dinâmicos.

A localização das infraestruturas territoriais, especialmente aquelas destinadas à circulação de pessoas e mercadorias, foi essencial à intensidade e à direção da propagação da doença. Não por outra razão, o centro urbano mais importante do Brasil, a metrópole paulista, registrou o primeiro caso da Covid-19. Num segundo momento, através da importação do exterior, a doença chegou às principais cidades médias do país, onde estão localizados aeroportos regionais importantes.

Nesse contexto, e num momento em que o país ainda não vivenciou o ápice da crise epidemiológica, a geografia é chamada a dar, principalmente, duas contribuições: 1) analisar em que medida as formas de organização do território condicionam a dispersão espacial do vírus, e; 2) produzir análises e informações que deem suporte à tomada de decisão e que, simultaneamente, informem a população sobre a situação local de saúde.

Este texto, em particular, pretende caracterizar e analisar a situação epidemiológica na cidade de Maringá, no estado do Paraná, face à Covid-19. Para tanto, são apresentados gráficos e mapas que 
retratam a situação da doença até o dia 30 de abril de 2020, ou seja, cerca de dois meses após a confirmação do primeiro caso no Brasil.

\section{SITUAÇÃO GEOGRÁFICA DE MARINGÁ}

O município de Maringá está localizado no noroeste do Paraná (figura 1), com uma área de aproximadamente $487 \mathrm{~km}^{2}$. Com altas taxas de urbanização $(98,4 \%)$, o município possui uma das principais cidades ${ }^{2}$ do interior do estado, com uma população estimada em, aproximadamente, 416.000habitantes.

Figura 1 - Paraná: População, 2019

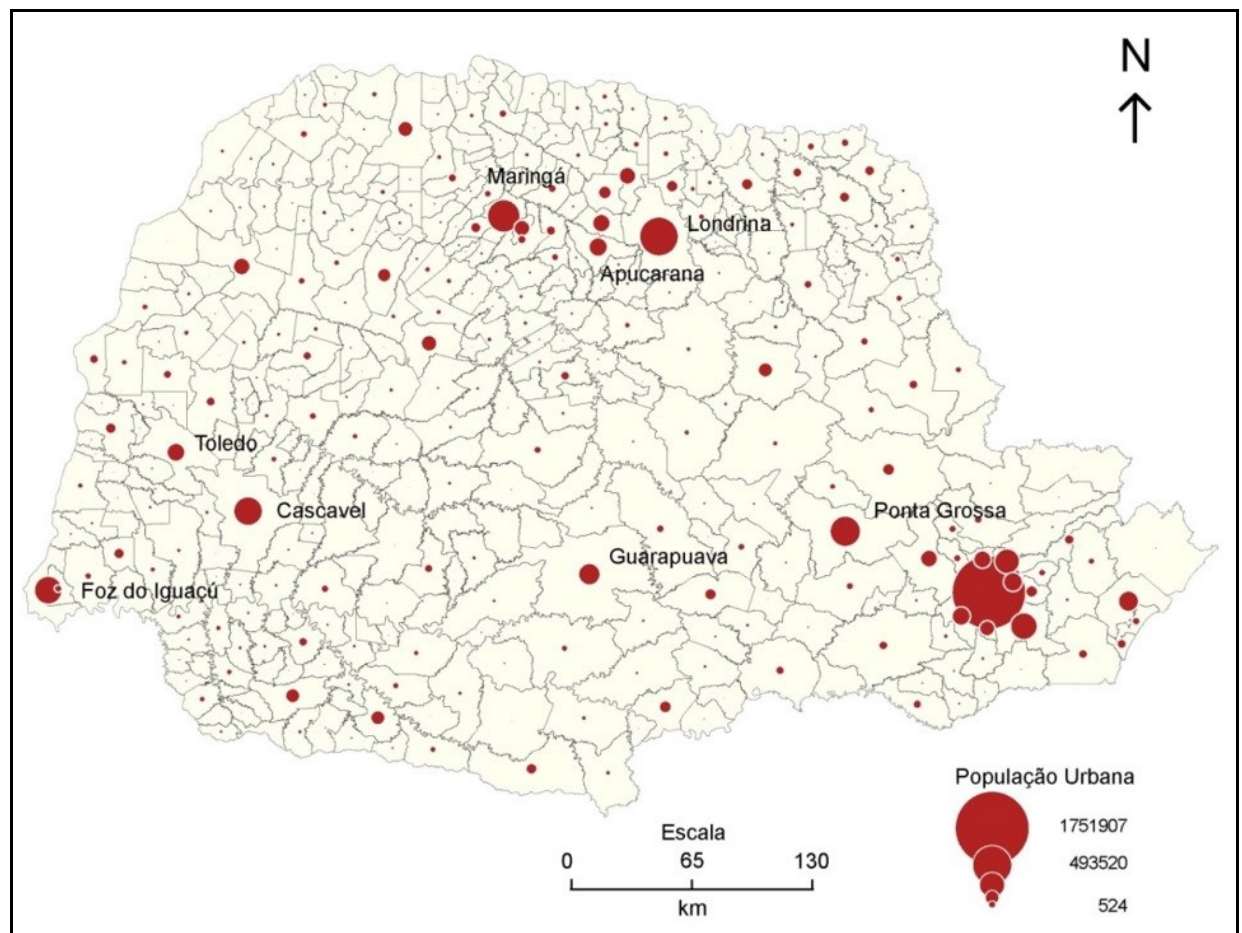

Fonte de dados: IBGE, 2019; Elaboração: Autores, 2020.

A situação geográfica (SILVEIRA, 1999) da cidade favoreceu a rápida chegada da Covid-19. O primeiro caso confirmado se deu antes mesmo de o Ministério da Saúde declarar "estado de transmissão comunitária" no Brasil, o que ocorreu em 20 de março de 2020, através da Portaria ${ }^{\circ}$ 454 (BRASIL, 2020a). Isso se deve ao fato de Maringá possuir um dos principais aeroportos do interior do estado do Paraná, que permite trânsito frequente de passageiros entre a cidade o exterior, apesar de não operar voos internacionais (BRASIL, 2018). Em função disso, o Aeroporto Regional de Maringá adotou protocolos sanitários específicos para passageiros oriundos do exterior (SBMG, 2020).

Além das conexões aeroviárias, Maringá está situada na confluência de eixos rodoviários importantes. Esses e outros elementos associados permitiram ao IBGE (2008) classificá-la como "capital regional", evidenciando seu papel articulador da rede urbana regional. A situação geográfica de Maringá, um nó da rede urbana regional e um importante centro prestador de serviços, para onde conflui a população dos municípios vizinhos, fez dela, simultaneamente, uma porta de entrada do

\footnotetext{
${ }^{2}$ A cidade corresponde à área urbana do distrito sede do município, conforme Decreto-lei 311 de 1938.
} 
vírus e um ponto de dispersão. Não por outra razão, a cidade acumula uma das maiores quantidades de casos do estado (Figura 2). Análises realizadas pela Fiocruz (2020a; 2020b) já apontaram para a lógica de dispersão do vírus no território brasileiro, ancorada nos principais nós da rede urbana.

Figura 2 - Paraná: Casos confirmados de Covid-19, 30/04/2020

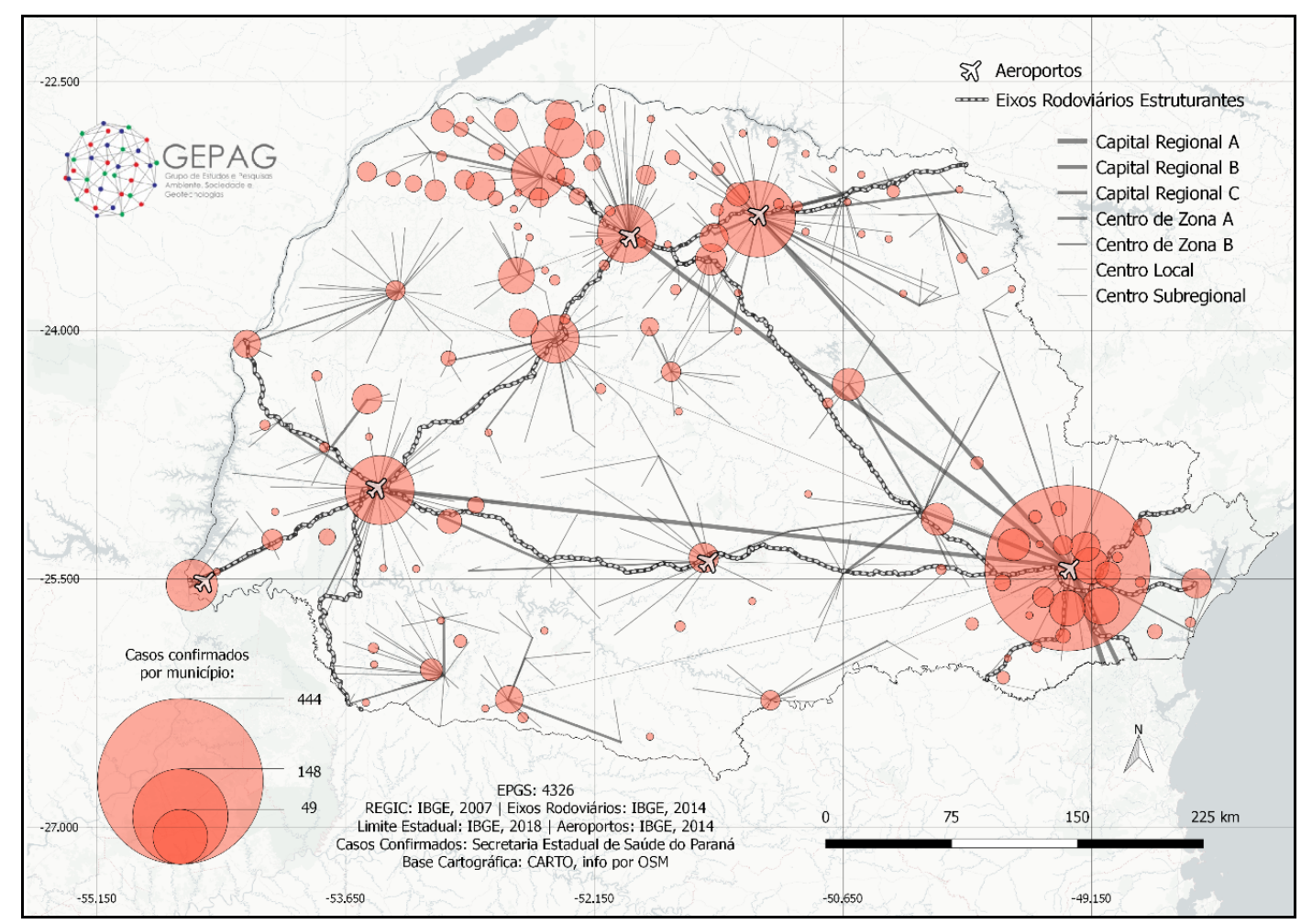

Fonte de dados: Secretaria Estadual de Saúde do Paraná; Elaboração: autores, 2020.

$\mathrm{Na}$ "Figura 2", pode-se observar que as cidades que estão nos nós das redes de transportes (rodoviários e aeroviários), foram, inicialmente, as mais afetadas pela pandemia. Em 30 de abril, Maringá contava 87 casos confirmados, atrás apenas de Curitiba (603), Londrina (102) e Cascavel (89). Adicionalmente, contata-se que a região onde Maringá está inserida possui uma grande quantidade de municípios infectados.

Cidades como Maringá, importante centro urbano em torno do qual a vida regional se articula, são fundamentais para compreender a dinâmica epidemiológica nos municípios vizinhos. O que se faz nesses centros urbanos regionais, portanto, tem reflexos no seu entorno.

Nesse contexto específico, este texto trata das ocorrências da Covid-19 no espaço intraurbano da cidade de Maringá, sem esquecer de suas articulações com outras escalas, das quais emerge o sentido de sua situação geográfica, bem como dos elementos que operam de modo latente às condições concretas de realização dos eventos de saúde na escala local.

\section{A COVID-19 EM MARINGÁ: contaminação hierárquica e difusão espacial intraurbana}

A primeira notificação por Covid-19 em Maringá ocorreu no dia 28 de fevereiro. Analisando o gráfico seguinte (Figura 3), é possível constatar que em três semanas (28/02 a 20/03), o número de 
notificações saltou de 01 para 100. Em seguida levou pouco mais de uma semana (21/03 a 30/03) para ultrapassar os 1000 casos. Até 30/04, a cidade acumulava 2370 notificações.

Figura 3 - Maringá: Evolução do número de notificações de Covid-19, 28/02 a 30/04/2020

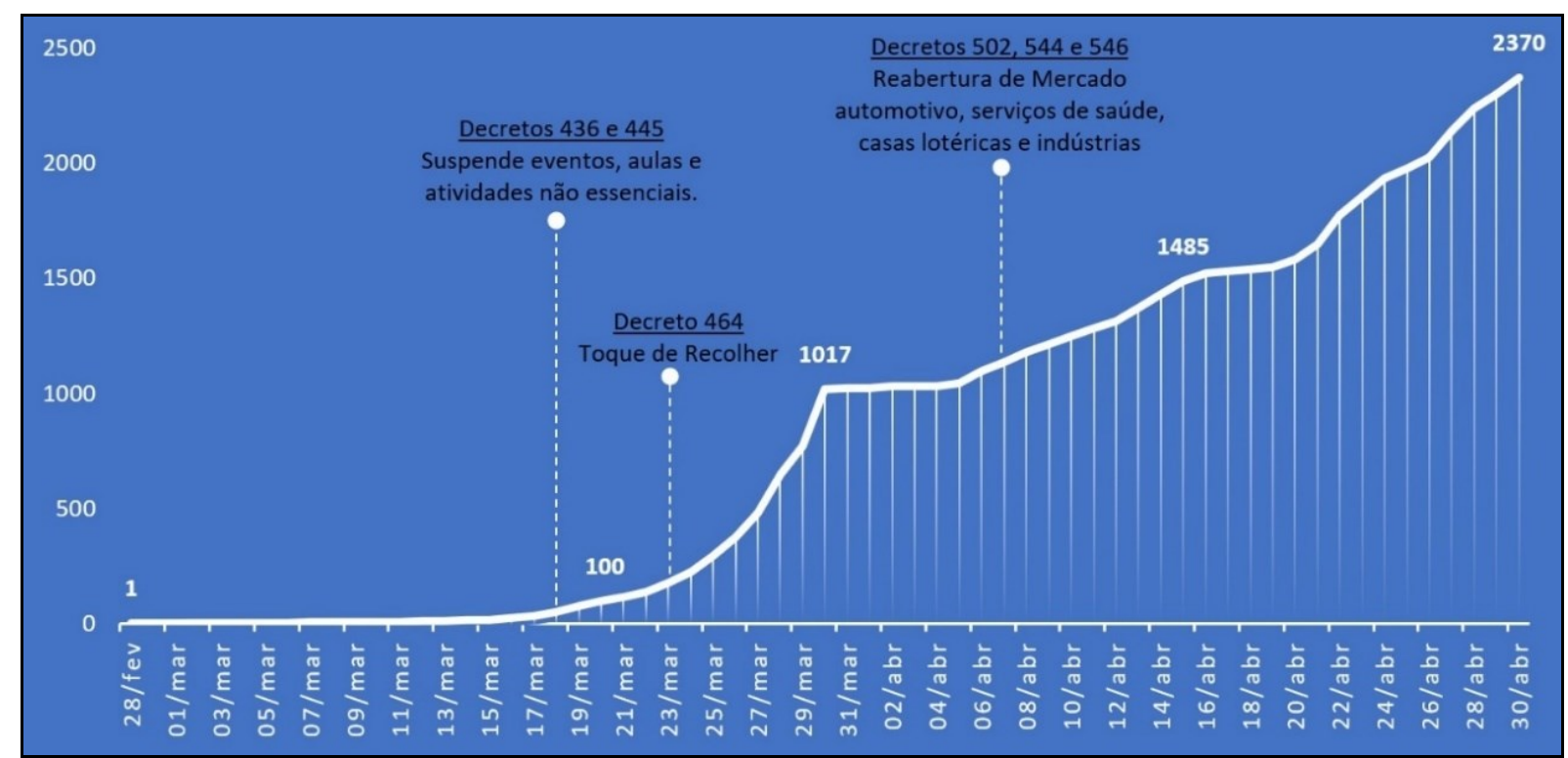

Fonte: Secretaria Municipal de Saúde de Maringá; Org. Autores, 2020.

As informações sobre notificações são importantíssimas para mapeamento e análise, pois o Brasil não tem feito testagem em massa, conforme recomenda a Organização Mundial da Saúde (WHO, 2020). Trata-se, portanto, de uma boa proxy para avaliação da dispersão da Covid-19, tanto no território nacional quanto no espaço intraurbano. Além disso, são essenciais em estratégias de avaliação da efetividade das medidas adotadas pela Administração Municipal.

No gráfico anterior (Figura 3), é possível notar que as primeiras medidas adotadas, mais especificamente aquelas contidas nos Decretos Municipais 436/2020, 445/2020 e 464/2020, produziram resultados em, aproximadamente, duas semanas. $\mathrm{O}$ incremento diário de casos notificados, que estavam em ritmo de aceleração, chegou a 245 em 30/03, caiu vertiginosamente a partir de $31 / 03$, para 5 novos casos notificados. No período de 31/03 a 05/04, aproximadamente uma semana, o incremento diário permaneceu baixíssimo, muito próximo a zero. Os efeitos puderam ser constatados, também, na taxa de transmissão efetiva $\left(R_{t}\right)$ baseada nos dados de casos conformados (Figura 4).

Esse fato está em sintonia com o que os epidemiologistas têm alertado (PREN et al, 2020), isto é, que os efeitos das medidas tomadas só podem ser constatados após duas semanas, aproximadamente. A partir do dia 06/04, os casos voltaram a retomar uma curva ascendente, mas não no mesmo ritmo de antes. Tensões envolvendo os agentes econômicos locais e a Administração Municipal de Maringá resultaram em paulatino afrouxamento das medidas de distanciamento social. Os decretos 502/2020 de 06 de abril, 544/2020 de 08 de abril e 546/2020 de 09 de abril, autorizaram, com recomendações sanitárias, a reabertura de vários setores do comércio local, o que aumentou a circulação da população pelos espaços da cidade. Como pode ser observado no gráfico (Figura 3), a partir do dia 21/04, a curva se tornou mais inclinada, indicando a aceleração no incremento de casos. Objetivamente, entre os dias 31 de março e 09 de abril, o incremento médio diário de casos era de 22. Entre os dias 10 de abril e 21 de abril, o incremento médio diário se elevou para 36 . Já do dia 22 de abril ao dia 30 de abril, a média sobe para 80 . A hipótese principal para explicar a mudança de 
comportamento no ritmo de notificações (que, em alguma medida, reflete a dispersão do vírus), está estreitamente vinculada às determinações contidas nos decretos municipais.

Figura 4 - Maringá: Taxa de transmissão efetiva $\left(R_{t}\right):$ 15/03 a 30/04/2020

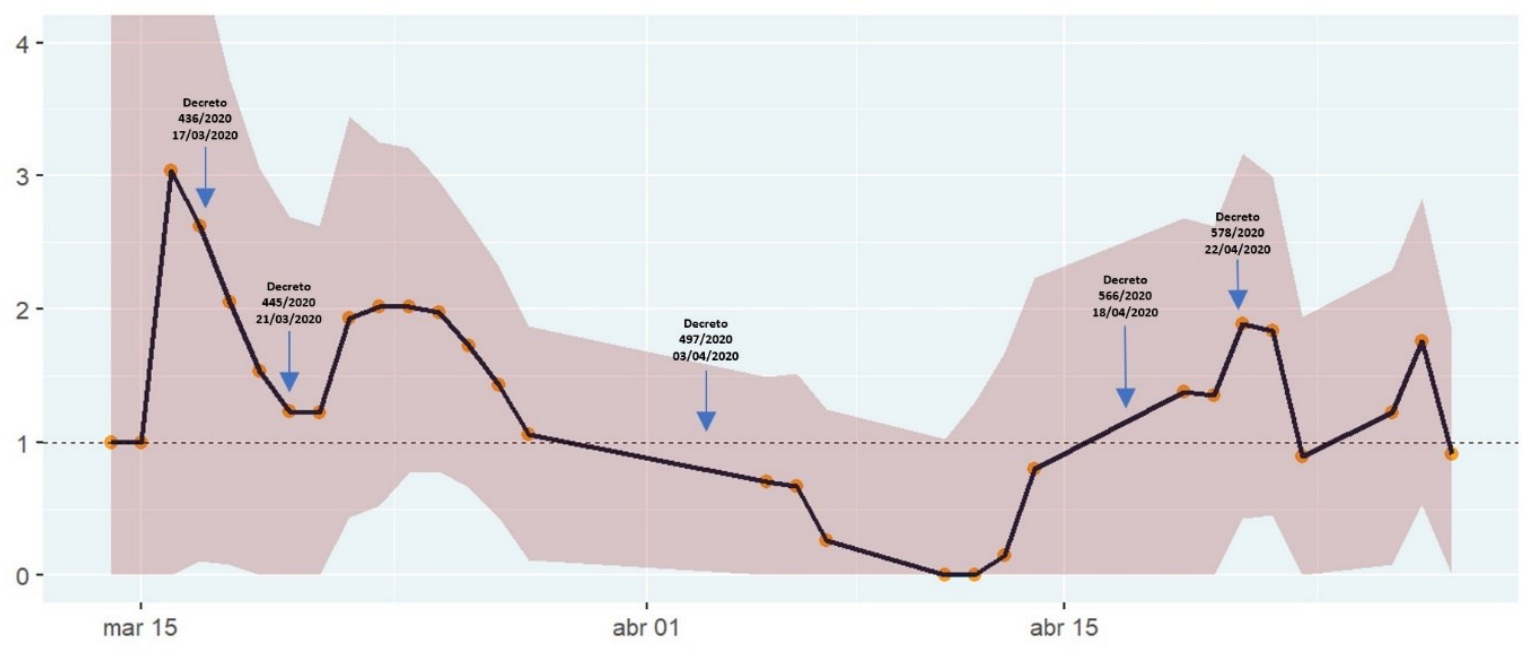

Fonte: Maringá/Secretaria de Saúde de Maringá, 2020b; Autor: Marcio Sommer Bittencourt, 2020.

As notificações por Síndrome Respiratória Aguda Grave (SRAG) (BASTOS et al, 2020) também têm sido muito utilizadas como proxy para dimensionar a Covid-19. De acordo com o Boletim Epidemiológico 05 da Secretaria Municipal de Saúde (2020b), Maringá chegou à sua $17^{\mathrm{a}}$ semana epidemiológica de 2020 com 3,2 vezes mais casos de SRAG comparativamente ao mesmo período de 2019 (Figura 5). Enquanto em 2019 foram 95 casos, em 2020 foram 303. Os casos notificados de Covid-19 no mesmo período foram 65 , ou seja, bem menor que a diferença registrada de casos de SRAG entre 2019 e 2020.

Foi destacado anteriormente que a difusão da Covid-19 está estreitamente associada aos espaços de maior densidade e fluidez. Nas diferentes escalas, nota-se que os espaços mais conectados com a escala do mundo foram os mais precocemente contaminados. Começou em Wuhan, uma importante cidade industrial da China, foi transmitida à Europa e aos Estados Unidos da América por meio das redes ferroviárias e aeroviárias e, desses territórios, chegou ao Brasil, mais precisamente à cidade de São Paulo, em 26 de fevereiro de 2020. Vê-se, portanto, que a cidade de São Paulo, o principal centro econômico brasileiro, devido à densidade de suas relações com o mundo, foi a primeira a registrar caso da Covid-19.

Em território brasileiro, o vírus, logo em seguida, passou a se disseminar pelo interior do país, inicialmente pelos principais eixos econômicos (São Paulo-Ribeirão Preto e São Paulo-Rio de Janeiro). Duas semanas depois, o vírus chegou ao território paranaense. Os primeiros casos registrados datam de 12 de março. Pouco tempo depois, os primeiros casos começaram a surgir nas cidades médias. Maringá, uma dessas cidades, teve seu primeiro caso de Covid-19 confirmado em 18 de março. É preciso destacar que, entretanto, não foi importado de São Paulo ou dos eixos mencionados, mas diretamente do exterior. Verifica-se, portanto, que a difusão do vírus no território se dá, basicamente, através das localidades centrais, seja por contiguidade ou contato de vizinhança (CATAO, 2016), seja saltando escalas (SPOSITO, GUIMARAES, 2020), de modo descontínuo, sem que necessariamente as hierarquias urbanas sejam respeitadas. 
Figura 5 - Maringá: Notificações de SRAG Hospitalizado e Casos Confirmados de Covid-19.

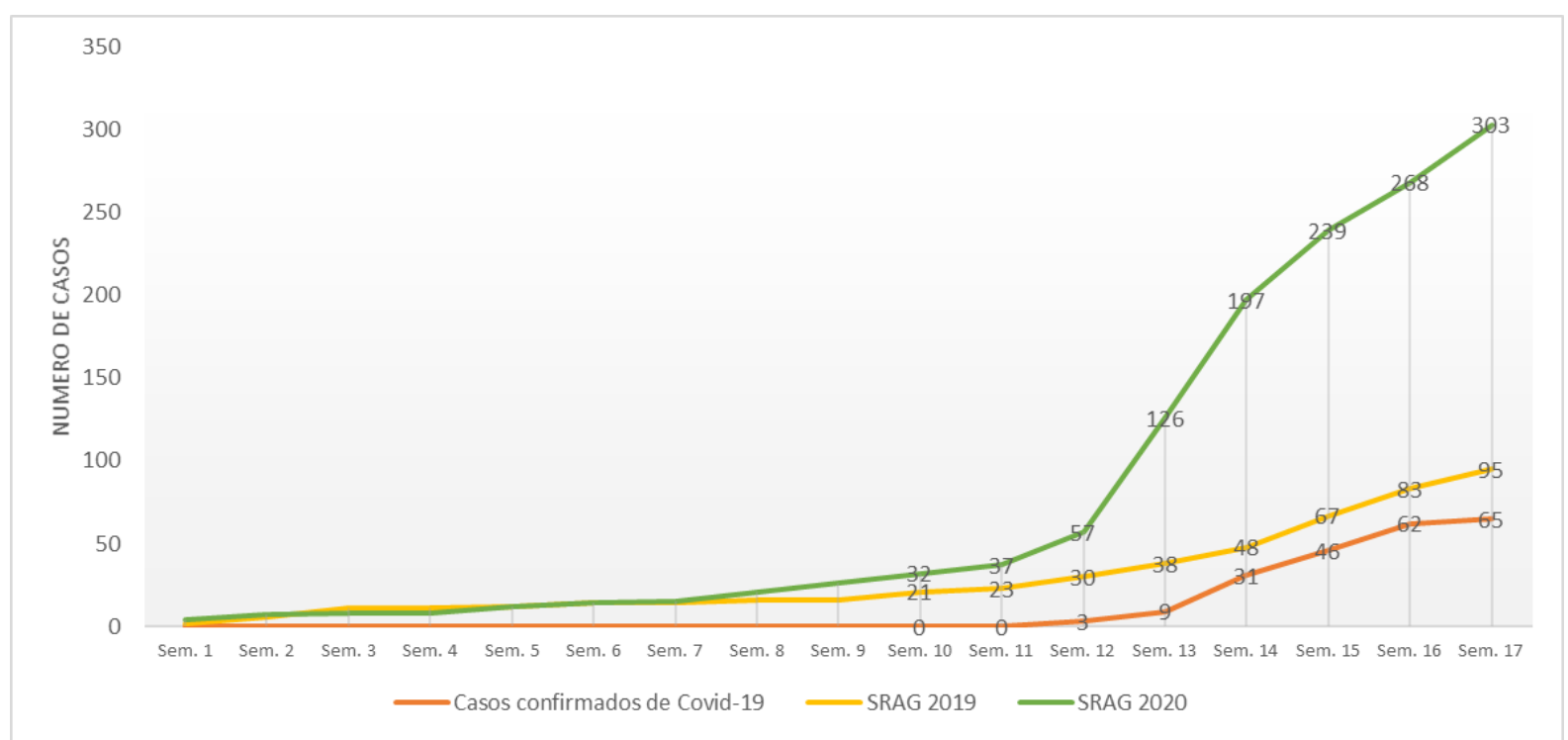

Fonte: Secretaria Municipal de Saúde de Maringá, 2020a. Adaptação: Autores, 2020.

O princípio da anisotropia (CASTRO, 2011) nos diz que o espaço não é homogêneo. As formas espaciais, nos lembra Santos (2004), são implantadas seletivamente no espaço de acordo com os interesses comandados por uma estrutura econômica que molda os modos de ser das coisas no mundo. Complementarmente a isso, Milton Santos (2008, p. 83) argumenta a existência de dois tipos de espaços: os espaços da pressa e os espaços da lentidão. Não são todos que podem participar dos espaços da pressa. Como lembra esse autor, a fluidez potencial tornada possível pelos meios técnicos (de transportes e de comunicação) disponíveis, é possível apenas para alguns. Somente uma pequena parte da sociedade, com os maiores rendimentos, pode ser transeunte no mundo. Para a grande maioria, isso permanece apenas no campo da possibilidade que não se realiza. Para Milton Santos, aí está, simultaneamente, sua força e sua fragilidade. A pandemia por Covid-19 é uma eloquente expressão desse argumento. Foi o sujeito veloz, ícone de um mundo globalizado, o vetor do vírus que atingiu a totalidade dos países, levando-o, portanto, às cidades médias. Os sujeitos lentos, por sua vez, tendem a ser ulteriormente atingidos pela doença, demandando pelos serviços de saúde no momento mais crítico da pandemia e em condições de resistência muito inferiores às classes mais abastadas.

Apesar de ser um sujeito do mundo, o sujeito veloz habita espaços específicos na "escala do acontecer". Esses espaços distinguem-se não exatamente por sua posição geométrica, mas essencialmente por suas características socioespaciais. Sujeito lento e sujeito veloz, portanto, não ocupam o mesmo lugar na cidade. A conexão do sujeito veloz com o mundo, que o tornou vetor da Covid-19, produziu uma geografia estreitamente vinculada aos espaços urbanos de maior rendimento e mais bem conectados. No caso de Maringá, ela coincide com a área central da cidade, onde predominou, nos primeiros dois meses, a maior incidência de casos.

O primeiro caso de Covid-19 foi confirmado em 18 de março, três semanas após o primeiro caso confirmado em território nacional. De acordo com a Secretaria Municipal de Saúde de Maringá (2020c, p. 5), a introdução do novo coronavírus no município ocorreu através de casos importados da Europa, América do Norte e Oriente Médio. Conforme o gráfico seguinte (figura 6), até o dia 30 de abril, Maringá registrou 87 casos positivos para a Covid-19.

O mapeamento dos casos revelou um padrão concentrado exatamente na área mais nobre da cidade (MARTINUCl, 2019) e isto persistiu até o final do mês de abril, ainda que no mesmo período comece a manifestar uma tendência de dispersão para as áreas periféricas, conforme pode se ver na "Figura 6". 
Figura 6 - Maringá: Casos confirmados da Covid-19, 18/03 a 30/04

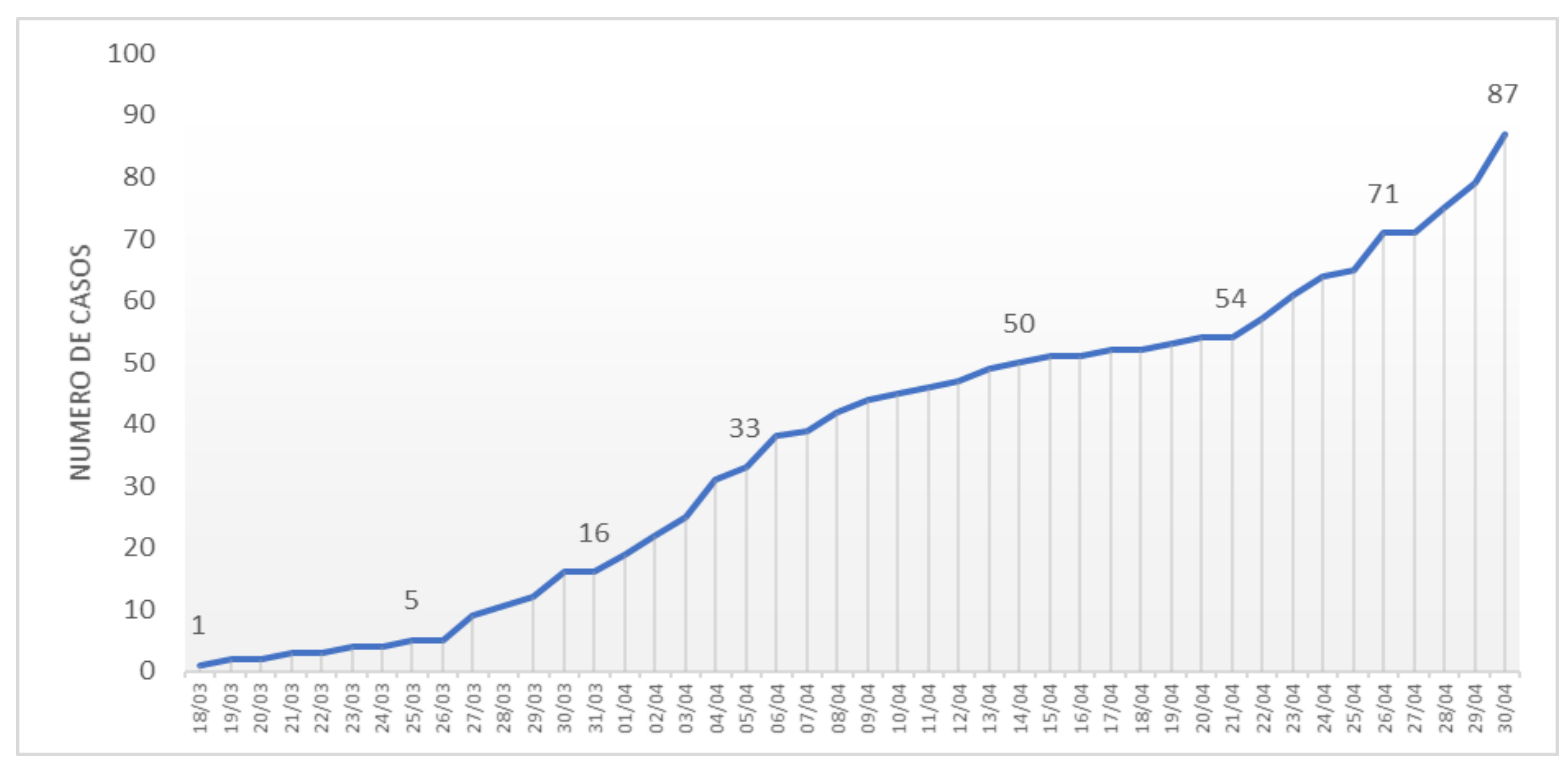

Fonte: Secretaria Municipal de Saúde de Maringá; Org. Autores, 2020.

A "Figura 7" apresenta dois momentos distintos. Em "A", o cenário de cerca de duas semanas após a confirmação do primeiro caso. Em "B", um mês após. Nela pode-se constatar a localização das maiores densidades de casos confirmados da Covid-19 em Maringá. A comparação das duas evidencia, após um mês, a tendência de espalhamento para as periferias urbanas. A dispersão para a zona leste da cidade, em particular, apresenta os maiores riscos, devido às características sociais e econômicas das populações que nela residem. São estruturas socioespaciais que se associam intimamente à transmissibilidade e à letalidade da Covid-19. Elas devem ser consideradas para a avaliação das situações de saúde e, consequentemente, para o planejamento das ações de enfrentamento dos desafios que se anunciam.

\section{ESTRUTURAS ESPACIAIS INTRAURBANAS DE MARINGÁ}

Estruturas podem ser entendidas como aspectos ou dimensões que revelam padrões de organização espacial e que condicionam os modos de ser dos eventos ou a forma como eles se realizam. De acordo com Milton Santos (2014), há várias estruturas. Entretanto, elas podem ser reduzidas a dois tipos: estruturas simples e estruturas complexas. As simples são basicamente aquelas que podem ser adjetivadas facilmente: demográfica, econômica, epidemiológica etc. Elas decorrem, portanto, da análise de variáveis de uma mesma classe. Corresponde ao esforço de análise em que a realidade precisa ser decomposta em partes.

As estruturas complexas, por sua vez, decorrem da natureza das relações das partes com o todo. Compreende, portanto, um nível de abstração mais elevado, frequentemente obtido com o esforço de síntese, que não se obtém, como lembram Milton Santos (2004) e Henri Lefebvre (1975), unicamente com a soma das partes. No presente texto, são apontadas algumas estruturas simples que, mesmo consideradas preliminarmente, têm a capacidade de moldar significativamente as características dos eventos de saúde, particularmente, os impactos decorrentes da Covid-19. É preciso capturar o sentido que está nas relações.

Três fatores são fundamentais para analisar a vulnerabilidade à Covid-19 nos territórios intraurbanos: 1) população idosa, como 60 anos ou mais; 2) densidade intradomiciliar, pelas dificuldades de distanciamento social, que implica maior risco de contágio e, portanto, valores mais elevados de " $R$ zero" (GANEM et al), e; 3 ) vulnerabilidade social. 
Figura 7 - Maringá: Dispersão dos casos confirmados de Covid-19: 29/03 a 30/04/2020

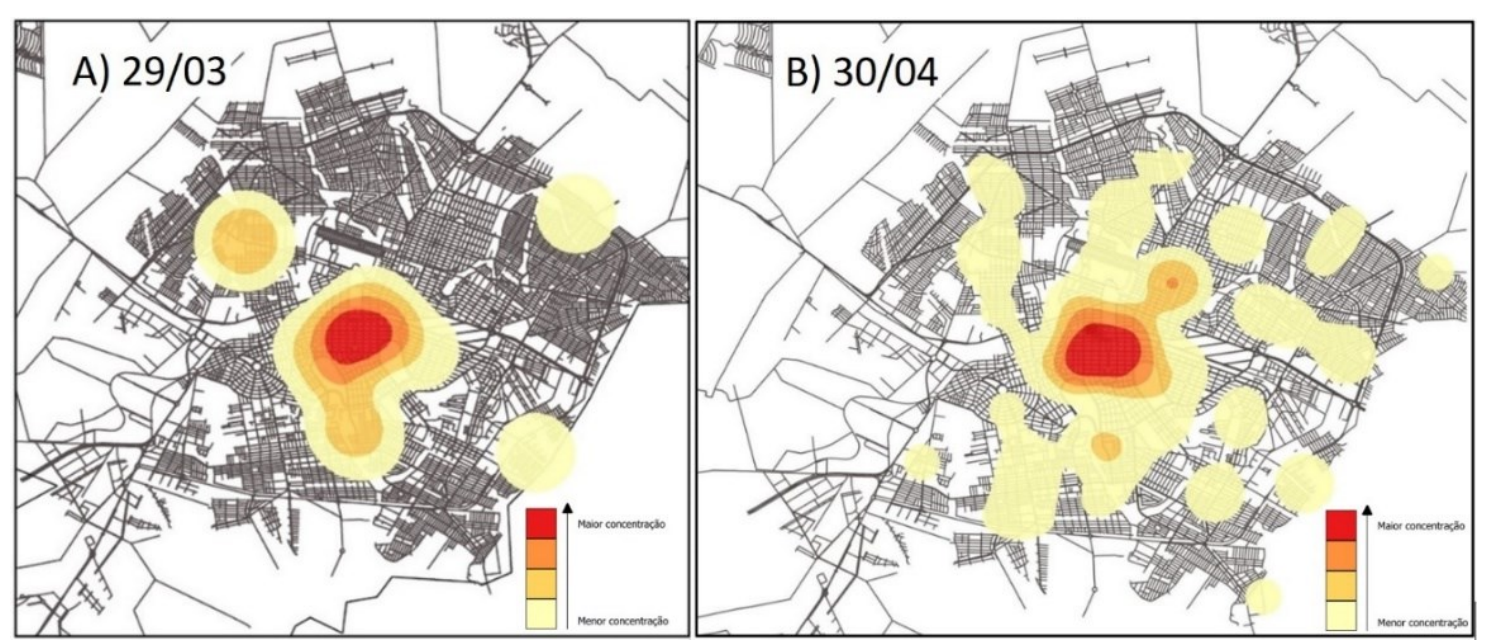

Fonte: Secretaria Municipal de Saúde de Maringá, 2020.

Análises realizadas nos quatro primeiros meses da pandemia de Covid-19 evidenciaram que as formas mais graves de adoecimento acometem especialmente indivíduos com 60 anos ou mais (ZHOU et al, 2020; BRASIL, 2020b). O mapeamento das populações que compõe essa faixa etária específica, portanto, é fundamental. No caso da cidade de Maringá, como ocorre em várias cidades médias brasileiras, a população idosa tende a concentrar-se nas áreas mais centrais do espaço urbano. Como pode ser percebido na representação (Figura 8), as maiores taxas de envelhecimento estão na área central de Maringá, correspondendo, sobretudo, às zonas 1, 2, 3, 4 e 5. Além da área central, como pode ser verificado, há um eixo que se estende na direção nordeste.

Figura 8 - Maringá: população com 60 anos ou mais, 2010

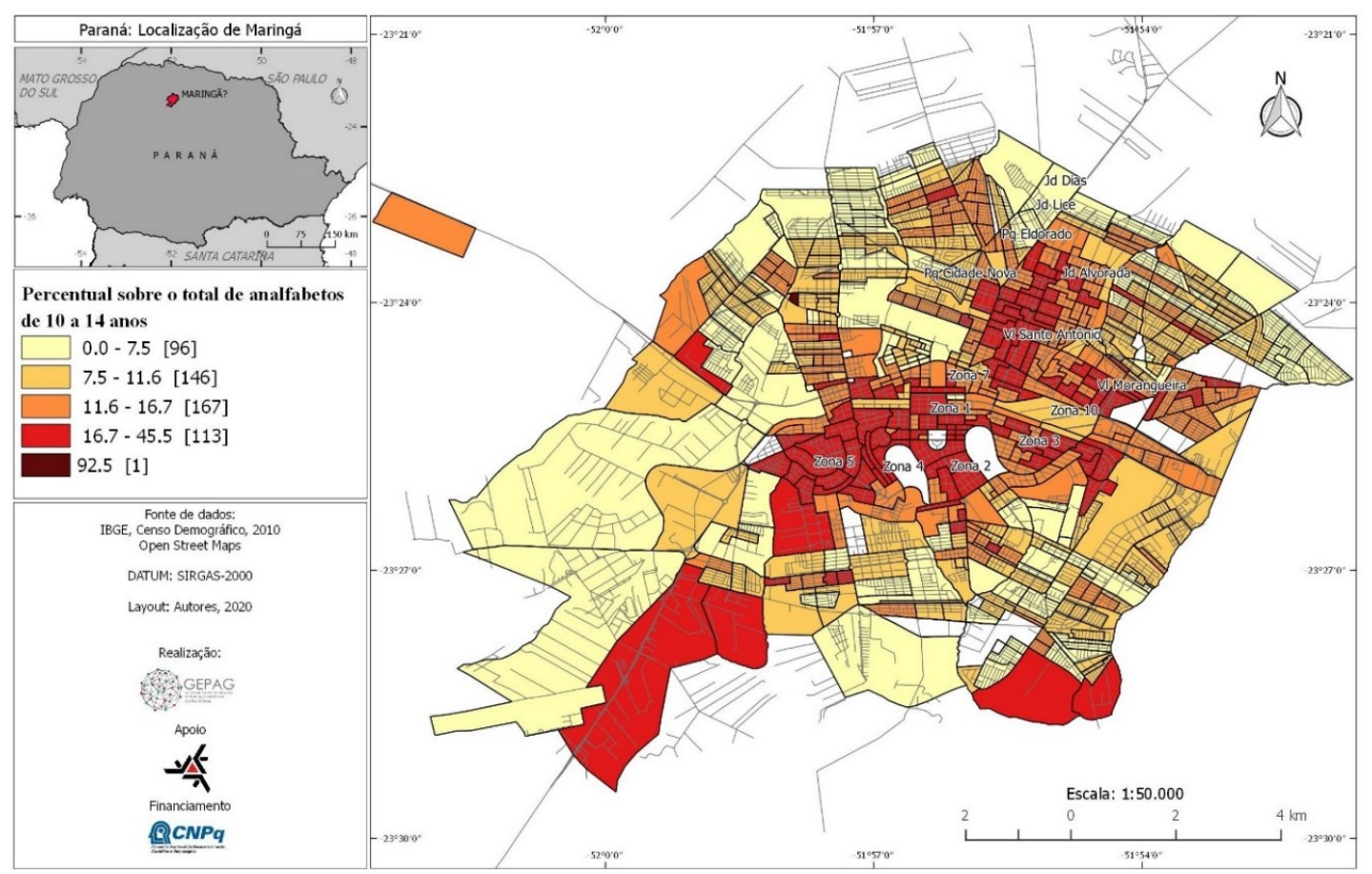

Fonte de dados: IBGE, 2010; Org. Autores, 2020 
Por se tratar de uma doença altamente contagiosa, dependente, portanto, da proximidade física entre indivíduos, é fundamental considerar a densidade de ocupação das habitações para a análise da Covid-19. O mapa a seguir (Figura 9), que representa a densidade intradomiciliar, é central nessa análise.

Figura 9 - Maringá: densidade intradomiciliar, 2010
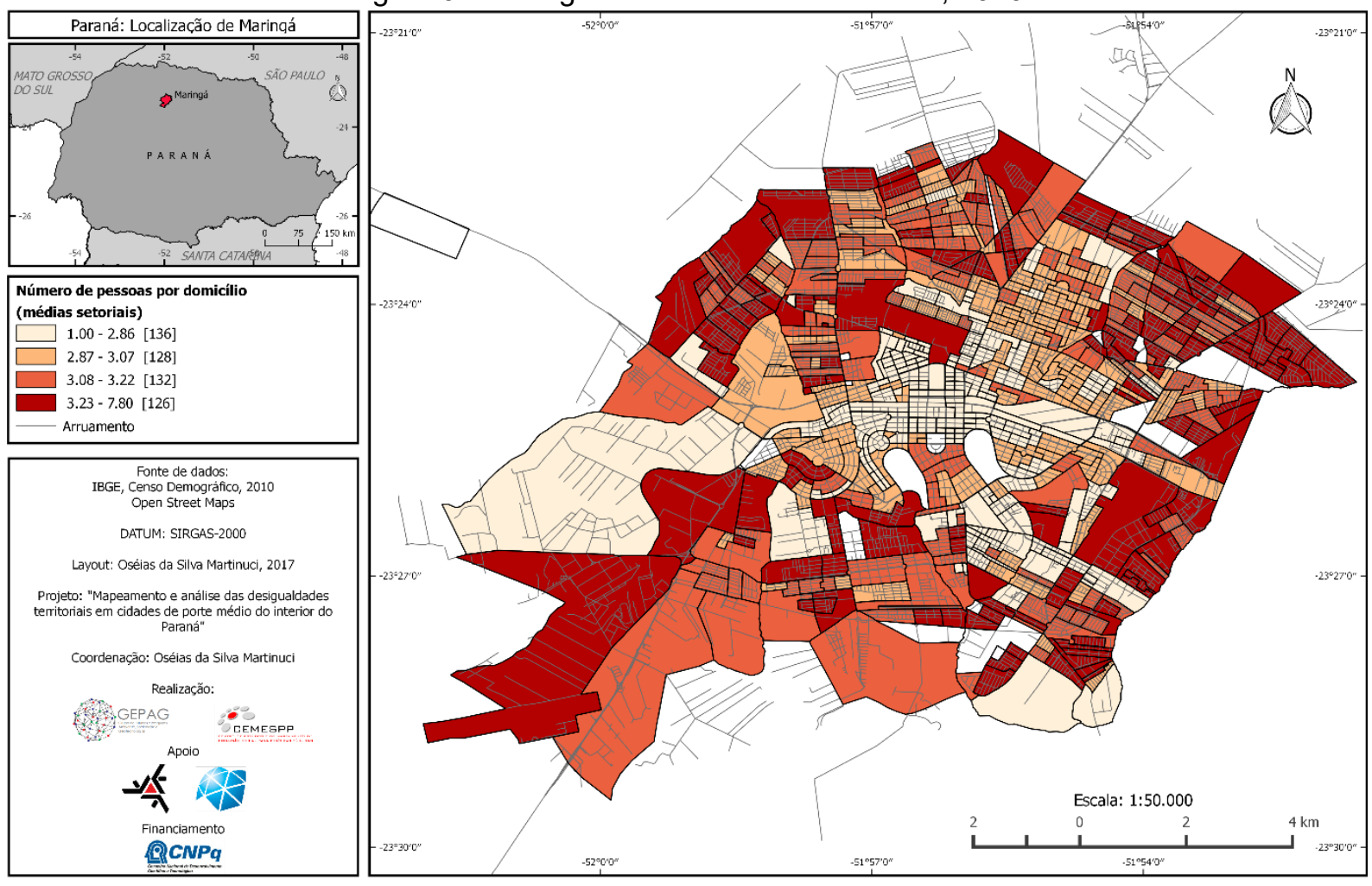

Fonte: Gepag/UEM, 2017

A análise das representações anteriores (Figuras 8 e 9), evidencia que as áreas com as maiores taxas de envelhecimento correspondem também às áreas com menores densidades intradomiciliares. Pode-se dizer, a priori, que os idosos na cidade de Maringá têm a favor de si um fator que alivia o risco de contágio, por ter, nessas regiões, menores dificuldades para manter o distanciamento social. As áreas periféricas da cidade, por outro lado, possuem as maiores densidades intradomiciliares. É possível notar que a região sudeste e a leste combinam os dois fatores, ou sejam, altas densidades domiciliares com altas taxas de envelhecimento.

Análises realizadas em grandes cidades como Rio de Janeiro e São Paulo já indicam que a doença aumenta sua gravidade conforme alcança as classes sociais empobrecidas (AHMED et al, 2020; SANTOS et al, 2020). No Brasil, portanto, as desigualdades socioterritoriais também se constituíram num fator explicativo da Covid-19, uma vez que o grau de letalidade nas populações mais vulneráveis é muito maior que entre as classes que detêm maiores níveis de renda e residem em bairros com menores densidades intradomiciliares e boa infraestrutura urbana. Por isso, é fundamental avaliar os diferentes níveis de vulnerabilidade a que estão submetidos os diferentes espaços de uma cidade.

O indicador de vulnerabilidade social (Figura 10) sintetiza uma série de fatores, como níveis de renda, de escolaridade, de condições habitacionais e demográficas (MARTINUCI, 2019), que podem agir como potencializador da gravidade e da transmissibilidade da doença. 
Essas três variáveis: taxas de envelhecimento, densidade intradomiciliar e vulnerabilidade social, portanto, são indispensáveis para avaliar os possíveis impactos que a Covid-19 produzirá entre as diferentes classes sociais dos espaços intraurbanos brasileiros.

Figura 10 - Maringá: níveis de vulnerabilidade Social, 2010

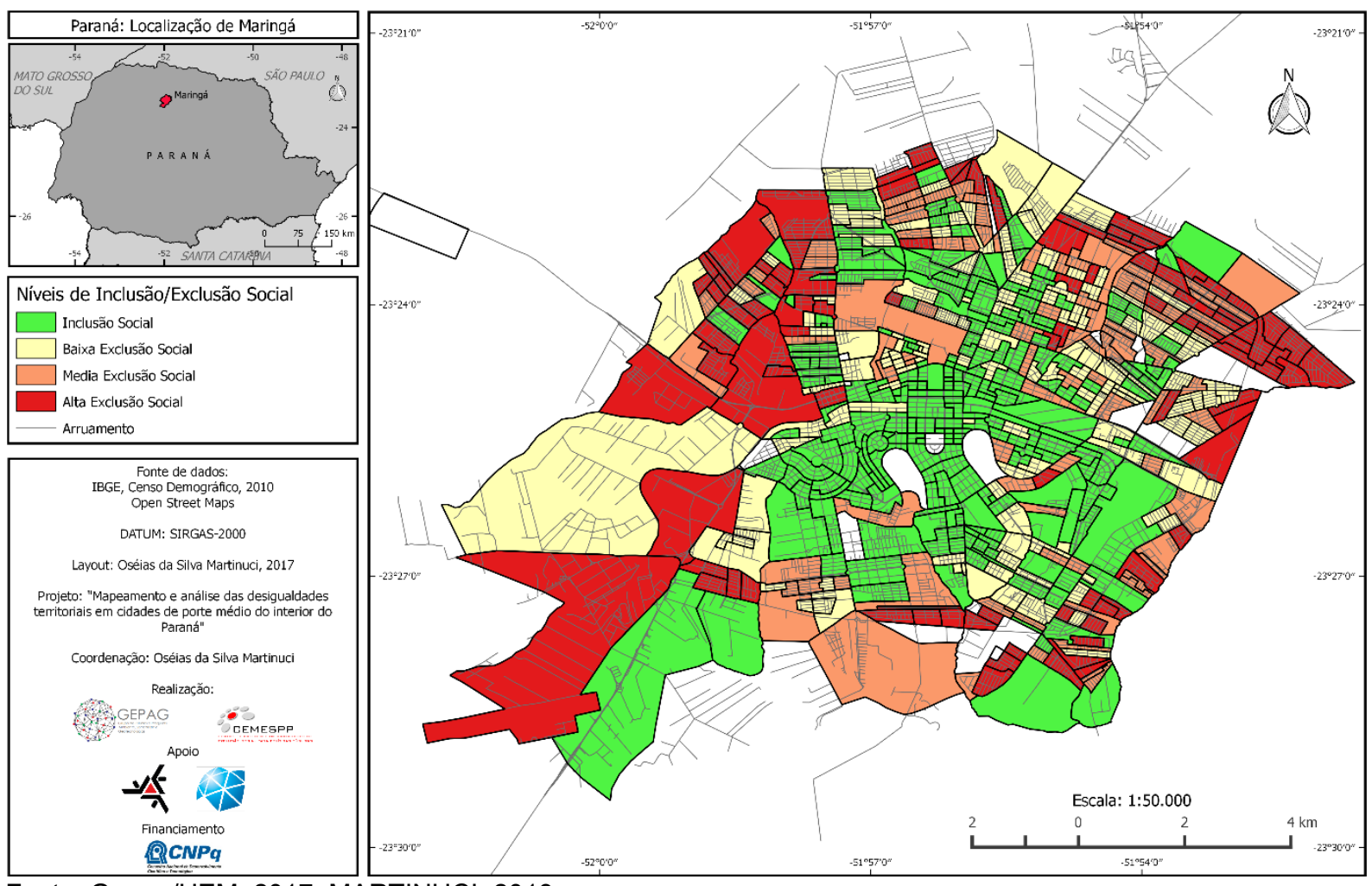

Fonte: Gepag/UEM, 2017; MARTINUCI, 2019.

Em Maringá, nos dos primeiros meses, a doença não atingiu tão fortemente os bairros populares. Apesar disso, demandam atenção antecipada devido à associação dos três fatores. Combinados, portanto, constituem em importantes indicativos do nível de risco ao desenvolvimento de formas mais graves de Covid-19 e, consequentemente, da letalidade da doença.

As classes mais abastadas, vetores do vírus SARS-COV-2 do exterior para o país, foram inicialmente contaminadas, não se expondo de forma significativa aos riscos de colapso do sistema de saúde, pois compuseram os momentos iniciais da curva epidemiológica. O aumento da proporção de casos da doença entre as classes sociais mais vulneráveis acarretará uma situação mais grave, sobretudo para os trabalhadores, pois estes encontrarão o sistema de saúde em uma situação mais crítica, num período correspondente ao pico da pandemia. Por ora, no segundo mês da pandemia, apesar do processo de dispersão para as periferias, na cidade de Maringá os casos estavam, em termos absolutos e relativos (fig. 11), concentrados nas áreas mais nobres.

\section{CONCLUSÃO}

A pandemia da Covid-19 fez a geografia do mundo se evidenciar. Como resultado, os geógrafos foram chamados a contribuir com análises tanto científicas quanto técnicas. Conhecer os fundamentos que estruturam o espaço geográfico e que condicionam a ação é indispensável para o estudo dos fenômenos da saúde. A pandemia pela qual passa o mundo é uma amostra eloquente dessa afirmação. Há fortes elementos que permitem afirmar não apenas que os eventos em saúde 
são altamente dependentes das condições impostas pelo espaço geográfico, mas também que a própria saúde, numa perspectiva de totalidade, é, também, espaço geográfico.

Figura 11 - Maringá: taxa de contaminação por Covid-19 em 30/04/2020

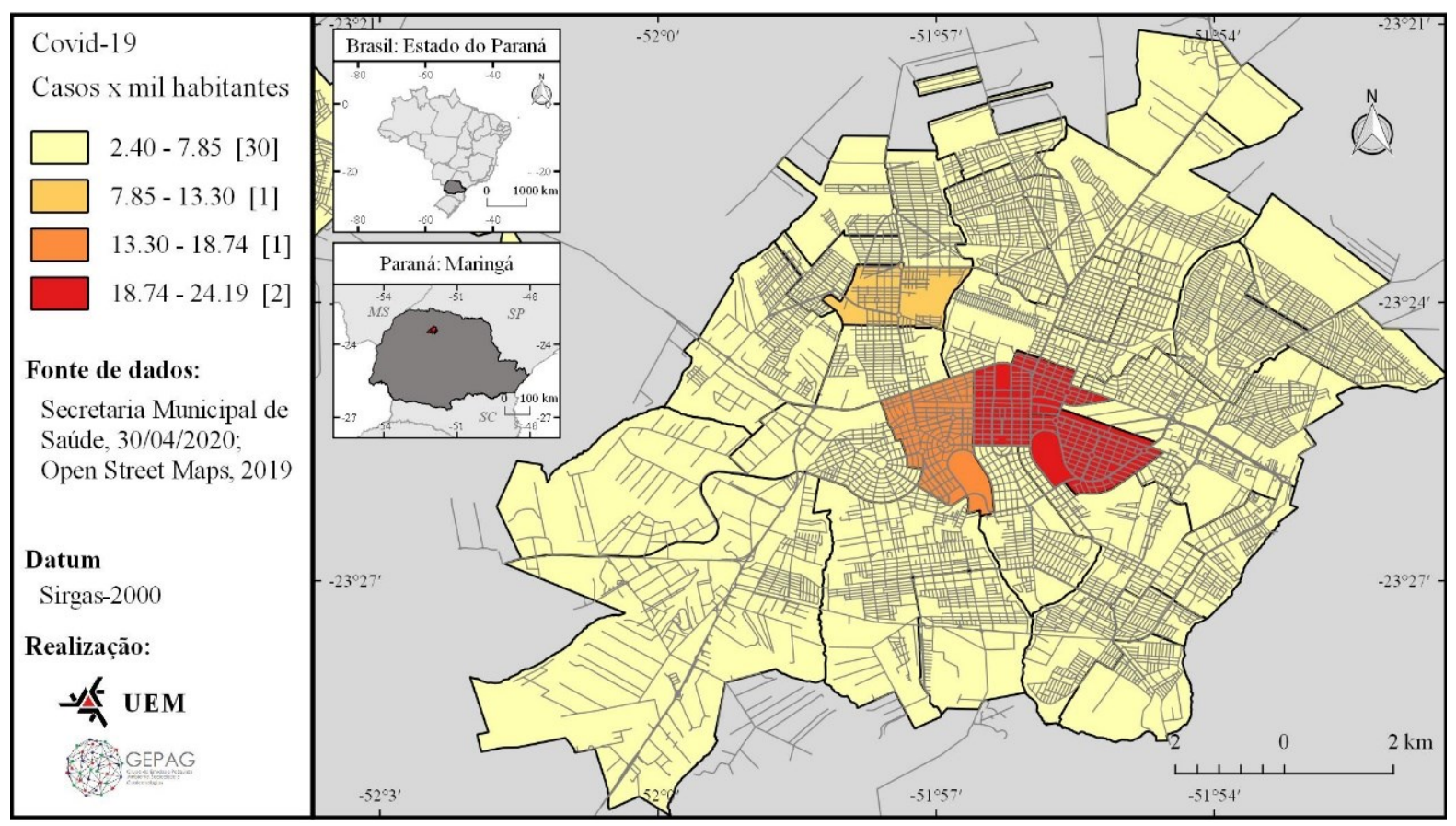

Fonte de dados: Secretaria Municipal de Saúde de Maringá; Org. Autores, 2020.

A análise da Covid-19 evidenciou:

1. O papel das classes sociais mais abastadas como vetor do vírus;

2. A associação do vírus aos espaços centrais nas mais diversas escalas: do mundo, da região, das cidades e dos lugares;

3. A contaminação precoce do centro econômico do capitalismo mundial, sobretudo, Europa e Estados Unidos;

4. O papel dos aeroportos na escala dos países. O vírus chegou aos centros econômicos nacionais mais vigorosos, no caso do Brasil a cidade de São Paulo, e se dispersou pelo interior através dos aeroportos regionais, contaminando logo em seguida as cidades médias, as principais portas de entrada ao interior, aos espaços lentos.

5. O padrão de centralidade se replicou na escala intraurbana, uma vez considerada a localização das moradias desses sujeitos contaminados com capacidade de alta fluidez na escala do mundo.

6. Após o estabelecimento da circulação viral a partir das áreas centrais das cidades médias, seguir-se-á a propagação da doença pela contiguidade, seja na direção das áreas onde residem as populações mais vulneráveis, seja na direção dos pequenos municípios.

No mês de maio de 2020, a pandemia da Covid-19 ainda está em curso. Isso significa que ainda há muito o que acontecer. A chegada às classes mais vulneráveis, por exemplo, exigirá um olhar atento por parte dos pesquisadores, dos gestores e, também, dos geógrafos. 


\section{REFERÊNCIAS}

AHMED, F.; AHMED, N.; PISSARIDES, C.; STIGLITZ, J. Why inequality could spread COVID-19. The Lancet Public Health, v. 5, n. 5, p. 240, 01/05/2020. https://doi.org/10.1016/S2468-2667(20)30085-2

BASTOS, L. S. et al. COVID-19 e hospitalizações por SRAG no Brasil: uma comparação até a 12a semana epidemiológica de 2020. Cadernos de Saúde Pública, v. 36, n. 4, p. 1-8, 2020. https://doi.org/10.1590/0102-311x00070120

BRASIL. Ministério da Saúde. Portaria n 454. Diário Oficial da União, Edição 55-F, Seção 1 (Extra), p. 1, 20/03/2020, 2020a.

BRASIL. Ministério da Saúde. Doença pelo coronavírus 2019. Boletim Epidemiológico (Especial), Brasília, v. 07, abr./2020, 2020b.

BRASIL. Secretaria de Aviação Civil da Presidência da República. UFSC: Florianópolis, 2018.

CATAO, R. Expansão e consolidação do complexo patogênico do dengue no estado de São Paulo. Tese (Doutorado em Geografia). UNESP: Presidente, 2016. 274f.

CASTRO, I. E. Problema da espacialidade da democracia e a ampliação da agenda da geografia brasileira. Rev. da ANPEGE, v. 7, n. 1, p. 291-305, out. 2011. https://doi.org/10.5418/RA2011.0701.0024

FIOCRUZ. Monitora Covid-19: nota técnica 1. Fiocruz: Rio de Janeiro, 2020a.

FIOCRUZ. Monitora Covid-19: interiorização da Covid-19 e as redes de atendimento em saúde. Fiocruz: Rio de Janeiro, 2020b.

GANEN, F. et al. The impact of early social distancing at COVID-19 Outbreak in the largest Metropolitan Area of Brazil. MedRix (The Preprint Server for Health Sciences), 15/04/2020. https://doi.org/10.1101/2020.04.06.20055103

IBGE. Região de Influência das cidades. IBGE: Rio de Janeiro, 2008.

LEFEBVRE, Henri. Lógica formal/lógica dialética. Rio de Janeiro: Civilização Brasileira, 1975.

MARINGA. Secretaria de Saúde. Boletim epidemiológico 06. PMM: Maringá, 08/05/2020, 2020a

MARINGA. Secretaria de Saúde. Boletim epidemiológico 05. PMM: Maringá, 17/05/2020. 2020b

MARINGA. Secretaria de Saúde. Boletim epidemiológico 03. PMM: Maringá, 17/05/2020, 2020c.

MARTINUCI, O. S. Desigualdade nas cidades de porte médio do interior do estado do Paraná-Brasil. In: Encuentro de Geografos de America Latina, 17., 2019, Quito. Anais eletrônicos... Quito, PUCE, 2016, p. 1-24. Disponível em: https://www.puce.edu.ec/sitios/egal2019/. Acesso em: 22 maio 2020.

PREM, K. et al. The effect of control strategies to reduce social mixing on outcomes of the COVID-19 epidemic in Wuhan, China: a modelling study. The Lancet Public Health, v. 5, n. 5, p. 261-270, 01/05/2020. https://doi.org/10.1101/2020.03.09.20033050

SANTOS, J. P.C.; SIQUEIRA, A. S. P.; PRAÇA, H.L.F.; ALBUQUERQUE, H. G. Vulnerabilidade às formas graves de Covid-19. Cadernos de Saúde Pública, Rio de Janeiro, v. 36, n. 5, p. 1-12, 2020. https://doi.org/10.1590/0102-311x00075720

SANTOS, M. Por uma outra globalização. Record: São Paulo, 2008.

SANTOS, M. Espaço e método. Edusp: São Paulo, 2014.

SANTOS, M. Por uma geografia nova. Edusp: São Paulo, 2004.

SBMG (Aeroporto Regional de Maringá). Coronavirus (Covid-19). Disponível em: http://www.aeroportomaringa.com.br/pt/noticias/CORONAV\%C3\%8DRUS (COVID-19). Acesso em: 22/05/2020. 
SPOSITO, M. E. B. Porque a circulação de pessoas tem peso na difusão da pandemia. Disponível em: <https://www2.unesp.br/portal\#!/noticia/35626/por-que-a-circulacao-de-pessoas-tempeso-na-difusao-da-pandemia>. Acesso em 08/05/2020.

ZHOU, F. et al. Clinical course and risk factors for mortality of adult inpatients with COVID-19 in Wuhan, China. The Lancet Public Health, v. 395, n. 10229, p. 1054-1062, 28/03/2020.

WHO. Strategic and preparedness and response plan. WHO: Geneva, 2020. 